\title{
EL EMPRENDEDOR (1805), NOVELA DE AVENTURAS ORIGINAL DE JERONIMO MARTÍN DE BERNARDO
}

\author{
Joaquín ÁLVAREZ BARRIENTOS \\ CSIC (Madrid)
}

En el panorama novelístico del siglo XVIII español destaca, entre las obras originales de ingenios nacionales, El Emprendedor, o aventuras de un español en el Asia, que se publicó en dos tomos en 1805 (Madrid, Imprenta de Vega y Compañía). A diferencia de lo que sucedía con la generalidad de los libros, éste sólo se vendía en Madrid, en las librerías de Alonso y Orea, según los anuncios en la prensa, que indican los puestos de venta en toda España.

El Emprendedor volvió a editarse, "corregida en esta segunda impresión", en 1829 (Madrid, Oficina de doña M⿳a Martínez Dávila), en un volumen. Se vendía en la librería de Amposta, calle del Príncipe, 5 y 6. En esta ocasión se presenta la lista de suscriptores, que sólo alcanzan el número de cuarenta, siendo dos de ellos mujeres y otros dos Juan Francisco Piferrer, "del comercio de libros de Barcelona" y Jacinto Hernández, "del comercio de libros de Toledo". En la misma edición "se han hecho las correcciones necesarias en el día" (pág. VII), que por lo que he podido constatar se reducen a regularizar la grafía y la puntuación, y a corregir erratas. En la misma nota donde se señala este hecho se comenta que Jerónimo Martín de Bernardo era "célebre autor". Hasta el día, y a pesar de esta celebridad, me ha sido imposible recabar información sobre el personaje que, por lo que dejó escrito en el prólogo a su "obra original", era madrileño, y que quizá fuera presbítero (AHN, Estado, 3235/13). Ninguno de los catálogos consultados sobre escritores de Madrid de los siglos XVIII y XIX ha dado respuestas positivas.

Lo que se sabe de su producción literaria es que, además de esta novela, tradujo la Vida de $M^{a}$ Antonia de Austria, sin conseguir licencia de impresión, y que publicó entre 1807 y 1808 los Ocios de un arresto, o correspondencia mitológica (Madrid, Vega y Cía, 3 vols.), especie de tratado mitológico de divulgación. 


\section{ARGUMENTO}

El Emprendedor es una novela de aventuras en la que la trama amorosa resulta fundamental, puesto que es el motor de la narración y el estímulo que mueve a los personajes por las diversas partes del globo terráqueo en que se desarrolla la acción, aunque no sea la única pasión que los motive. Su argumento es el siguiente:

Mahamut, el protagonista, es un médico turco que vive en Basora; es famoso y rico, pero tiene mal de amores: busca en los bazares y harenes a su amor perdido. Por un azar conoce a Ismael, "árabe del desierto", que le pide dinero para comprar a Celfa, que es su hermana, secuestrada dos años antes en desigual pelea. Sabemos que hasta el día en que fue robada habían vivido en su tribu como enamorados, y que, cuando fueron a casarse, la esclava de confianza confesó su relación familiar.

El cadí de Basora llama a Mahamut para que le cure. El médico lo hace con rapidez y eficacia, y las alabanzas y el agradecimiento que cosecha le atraen la envidia del agá, que le llama a su vez para que sane a su primera mujer. Cuando Mahamut se presenta ante el agá, discuten y llegan a las manos, provocado por éste. De resultas de la pelea, Mahamut es preso. Su esclavo Alí consigue huir, y junto con los otros criados, Ismael y Celfa, abandona la ciudad para esconderse en una cueva. A salvo, deciden que Ismael indague qué ha sido de Mahamut; entre tanto, el pueblo de Basora, conocedor de las virtudes del médico, protesta por su encarcelamiento. Hay grandes tensiones en la ciudad, y además, se propaga la peste, lo que lleva a que se le reclame con más insistencia y se critique a los que le apresaron. Se llega a un motín, que el agá quiere reprimir con violencia para matar a Mahamut en la confusión. En medio de ésta, Ismael, Ibrahim (hijo del cadí y amigo de Mahamut) y otros van a la cárcel a defenderlo. Allí se da una estupenda batalla, que termina al llegar el bajá. El agá huye y esa misma noche rescatan a Mahamut. Antes han socorrido a una dama en apuros. De vuelta a la cueva ven a dos hombres discutiendo en el camino, resultan ser el agá e Ibrahim. El primero quiere matarlo pero es Celima, la dama socorrida, quien mata de un disparo al agá: sabemos que Celima era su esposa, pero a quien quiere es a Ibrahim.

A la mañana siguiente, éste informa a su padre, el cadí, y al de Celima, de los hechos. Celfa cuenta su historia como esclava. Esta narración incluye el encuentro con la que sospechamos es la desaparecida amada de Mahamut, que se hace llamar Malheureuse. Ibrahim y Celima se casan y van a Constantinopla con el cadí. Semanas después Mahamut, tras detener el avance de la peste, inicia el mismo viaje, acompañado de sus criados, de Ismael y Celfa.

El barco en que viajan es de un joven capitán francés, que también cuenta su historia de amor contrariado. [Con la narración de esta historia se cierra el primer tomo y se abre el segundo en la primera edición; no así en la segunda, que no parte este relato]. Tormeiita en alta mar; la fragata tiene una vía de agua que les hará naufragar irremediablemente, pero Mahamut e Ismael se lanzan al 
mar para taponarla. Lo consiguen tras luchar con el mar y quedar muy maltrechos, lo mismo que el esclavo Alí, que también participa en la hazaña. Curación de los heridos. Mahamut narra su historia: es español, madrileño y noble, con estudios universitarios en Sevilla. Sus desgracias comenzaron cuando, para no separarse de su enamorada Elisa, que debía viajar a Mallorca, se embarcó de incógnito. Durante la travesía unos piratas los apresan y venden en Túnez a amos distintos. Él es comprado por un tunecino enfermo al que sana y que, en pago, le da la libertad. Así inicia su peregrinación por las ferias de esclavos más importantes y se dirige a Persia, pues sabe que Elisa ha sido vendida a un persa. Termina así su narración.

Llegan a Moca, desembarcan y abandonan al capitán francés. Toman otro barco hacia Suez; tras diversas peripecias, arriban a El Cairo y de allí a Alejandría, donde desencantan una casa. Por fin entran en Constantinopla; son recibidos por el cadí, ahora importante personaje de la corte, con gran alegría. Mediante casualidades, y gracias a sus conocimientos médicos, Mahamut penetra en el harén del sultán y allí, naturalmente, se encuentra Elisa, a la que consigue rescatar con la ayuda de Ismael. Éste, Celfa, Mahamut, Elisa y los esclavos del médico inician viaje hacia España. Antes de zarpar, Sísifa, la esclava que había cuidado a Ismael y Celfa, y a la que encontraron en Constantinopla, confiesa que sólo son primos, no hermanos, con lo que podrán casarse; después muere. Llegan a Madrid, tras hacer escala en varios puertos mediterráneos, entre ellos Marsella, donde coinciden con el joven capitán francés, que por fin va a contraer matrimonio con su amada. Ya en Madrid, Mahamut -ahora Antonio Ramírez-se encuentra con su familia, los árabes se convierten al cristianismo y las parejas se casan.

El itinerario seguido por los personajes es el siguiente: Basora - Bandar Abbay - Diu - Moca - Suez - El Cairo - Alejandría - Constantinopla - Sicilia Marsella - Nimes - Barcelona - Madrid. El viaje de Mahamut, desde sus primeras peripecias, dura tres años.

\section{CONTEXTO LITERARIO}

Como se desprende de este resumen, la novela se articula con el esquema de relatos entrecruzados de origen griego, y sobre este soporte una narración ágil de tono cervantino. De hecho, algunas de las historias que protagonizan los personajes y el modo de contar llevan a pensar que el autor se inspira en relatos españoles del siglo XVII. En la época, como se verá luego, se relaciona la novela con el Persiles, y algunas de las actitudes de los personajes con conductas caballerescas (renovadas) de la novela antigua. Esto es lo que a veces lleva a situar la acción entre el final del siglo XVII y los comienzos del XVIII, ya que, aunque en general los valores que se presentan son propios del siglo ilustrado, hay detalles, como el juego de sortija, la forma de presentar los duelos, la presencia de los piratas y un cierto color local en las descripciones de las ciudades españolas por las que transita Mahamud antes de salir de España, 
que hacen pensar en el Siglo de Oro. Desde este punto de vista, podríamos entender El Emprendedor como novela histórica, género a menudo fronterizo con el de la novela de aventuras. Sin embargo, en esta novela son más las diferencias que las semejanzas con la novelística española anterior.

Por otro lado, Martín de Bernardo conoce muy bien la zona de Oriente donde se desarrolla el relato, así como los alrededores de París, donde se desenvuelve la muy larga historia de amor del capitán francés que los traslada hasta Moca. Cabe pensar, pues, que el autor viajó por esos lugares de Oriente, quizá como médico o tal vez como miembro de las expediciones que llegaron a Constantinopla en los años ochenta, y que también vivió en París, o que algunas de esas historias intercaladạs están tomadas de otros textos novelescos y de libros de viajes de la época. En concreto, en 1753 se publicó el relato Le solitaire espagnol ou mémoires de D. Varasque de Figueroas, que no he podido localizar, que tuvo una nueva impresión, extractado, bajo el título Aventures d'un espagnol, en 1787, formando parte de la colección Voyages imaginaires, visions et romans cabalistiques, publicada en Amsterdam-Paris, entre 1787 y 1788 . Otros relatos orientales, no todos imaginarios ni de ciencia ficción, se publicaron en Francia a lo largo del siglo XVIII, y es posible que Martín de Bernardo, que también tradujo alguna obra francesa, los conociera y empleara para inspirarse y ambientar su novela. Desde luego, a estas posibles fuentes pueden añadirse las narraciones españolas del XVII que se desarrollan en Oriente, y con más seguridad el Viaje a Constantinopla en el año 1784 de José Moreno, publicado en 1790, y la Idea del imperio otomano de José Solano Ortiz de Rozas, del año 1793. Ambos libros son el resultado de viajes a la capital turca con motivo de la firma de la paz con el imperio turco en 1783: el de Moreno en 1784, el de Solano en 1786 y 1787 . En ambos libros se incluyen grabados de los monumentos más importantes de Constantinopla, planos de la ciudad, y capítulos dedicados a describir la capital, las costumbres turcas y los hábitos de vida en el harén, que pudieron servir a Martín de Bernardo. El Viaje de Turquía de Cristóbal de Villalón, publicado en 1557, podía tal vez estar en la memoria del autor, si tenemos presente que su protagonista también era, como Mahamut, médico. Sin embargo, no parece existir ninguna otra relación entre ambas historias.

El viaje que en 1803 inició Badía y Leblich bajo el nombre de Alí-Bey por el norte de África y por zonas del cercano oriente no puede considerarse un incentivo para Martín de Bernardo, pues su novela estaba escrita antes de 1801 , que es cuando se le concede licencia de impresión, concretamente el 29 de Julio (AHN, Consejos, leg. 5567/8), si bien resulta una curiosa coincidencia -o un dato tomado de la realidad-que tanto Alí-Bey como los protagonistas de $E l$ viaje de Turquía y El Emprendedor fueran médicos.

Esto, sin embargo, no debe restar originalidad a El Emprendedor, o aventuras de un español en el Asia, la cual es proclamada por su autor desde la portada y fue objeto de ácida ciética. Todos los escritores emplean materiales, ya librescos, ya de la realidad, a la hora de componer su obra, y Martín de 
Bernardo los emplea para ambientar su relato y hacerlo creíble gracias a los numerosos detalles de carácter pintoresco, pero también verista, que incorpora, aunque sin exagerar lo exótico ${ }^{1}$. Se quiso quitar importancia a la obra observando que era un simple y tardío ejemplo del género narrativo bizantino. Enfocarlo así es no apreciar lo que de novedoso tiene el relato y las diferencias existentes entre la novela bizantina y la de aventuras ${ }^{2}$. Martín de Bernardo escribe, sirviéndose del relato de aventuras, lo que se llamaba en la época una "novela española" o a la española, a diferencia de lo que eran novelas "inglesas", caracterizadas por el predominio de lo sentimental. Una muestra de esta clase de narrativa lo encontramos algunos años antes, en 1798, cuando la viuda e hijo de Marín publicaron en Madrid una obra titulada La noche entretenida, que constaba de tres novelas cortas: El solitario de las Ardenes, "novela francesa"; Morton y Susana, "historia inglesa"; y Alfonso y Feliciana, "novela española". La de Morton y Susana es el relato de las desgracias que ocasiona la extremada sensibilidad de los protagonistas; la de Alfonso y Feliciana se desarrolla en el Mediterráneo, con una mujer que busca a su amante, y fuertes recuerdos de las narraciones de cautivos. Es en esta tradición narrativa en la que se encuadra nuestra novela, proponiéndonos unos modelos castizos, y no en la línea narrativa sentimental, criticada por muchos al considerarla extranjerizante y peligrosa. El mismo autor hace referencia a ello, al tiempo que expresa los motivos que le llevaron a escribir su novela:

La mayor parte [de las publicaciones] son traducciones de los idiomas francés e italiano, cuyas historias, novelas, cuentos y viajes han tenido más aprecio entre la juventud de uno y otro sexo, siendo muy extraño que nuestros escritores, viendo la afición a esta clase de lectura, no se hayan dedicado a escribir originales, que por medianos que fuesen a lo menos serían acomodadas sus obras a nuestro carácter, leyes y costumbres, que las harían más útiles y divertidas, evitando en ellas que las pasiones fuertes, agitadas ideas y catástrofes negras y sangrientas que escribieron los extranjeros, propias para excitar el horror y el terror en sus países, endureciesen los generosos corazones de la juventud española, imprimiendo además en su memoria los medios de delinquir, algunos tan nuevos, que tal nunca hubieran ocurrido a la imaginación de sus lectores ${ }^{3}$.

\section{COSMOPOLITISMO Y RELATIVISMO DEL RELATO}

Sin embargo, en esta novela hay también pasiones fuertes, aunque tratadas de un modo positivo, y episodios terroríficos y emocionanates, en los que no se cargan las tintas. Por otra parte, este sentido nacionalista de la novela, que se relaciona con la creencia de que fue en España donde nació o se mejoró el

1. Una síntesis sobre la presencia de lo exótico en la literatura española del siglo XVIII se encuentra en Lafarga, 1994.

2. Para las relaciones y diferencias entre ambos géneros, véanse Batjín, 1985 y García Berrio-Huerta Calvo, 1992.

3. Las citas se hacen por la edición de 1805 (I, pp. 3-4). Entre las otras motivaciones que le llevan a escribir está el que quiere dar a los literatos un ejemplo de este tipo de novelas, "este ramos de literatura, conociendo que ella es el estímulo y primer escalón para entrar en las ciencias" (I, pág. 5). 
género "romancesco"4, no lleva a su autor a caer en el etnocentrismo al describir la civilización oriental. Al contrario, a lo largo de la narración da muestras de su imparcialidad, como había prometido en la Advertencia -"resolví pasear a mis lectores desde los confines del Asia hasta nuestra villa y corte de Madrid, indicando los absurdos de aquellas regiones, y celebrando lo bueno de ellas" (I, pág. 5), aunque al final los personajes árabes abandonan su religión y se convierten al cristianismo, si bien esta conversión en ningún momento se impone sino que surge como un deseo de los propios individuos, estimulados por el buen ejemplo de Mahamut ${ }^{5}$. Puede interpretarse como un ejemplo de la tolerancia que respira el relato, tanto como una consecuencia del desarrollo narrativo. Con la misma objetividad, y siguiendo el criterio formativo, se comparan costumbres, vicios y virtudes nacionales. Merece la pena destacar, como muestra de la resolución que se da a dicho objetivo, las siguientes reflexiones: "Los árabes [...] no podían concebir cómo la civilización, al propio tiempo que perfecciona al hombre, haciendo brillar sus virtudes, por el contrario, al que no tiene ninguna le hace un monstruo más temible que los que produce el desierto" (II, pág. 28). Para explicarles esta aparente contradicción, Mahamut, "que no desperdiciaba momento para su instrucción", les hace ver que "los perversos eran los mismos en todo lugar, más o menos perjudiciales, según los motivos y costumbres de los parajes donde habitasen; que la civilización, es verdad, proporcionaba arbitrios a la malignidad, pero que esta misma civilización los había previsto anticipadamente, para lo cual había establecido justas leyes que castigaban los criminales, asegurando los derechos y seguridad de honrados ciudadanos" (II, pp. 29-30) ${ }^{6}$.

Desde luego, su objetivo es deleitar instruyendo, pero de modo que la instrucción y la moral no interfieran en el relato: "las aventuras son verosímiles y pictorescas [sic], mezclando en todo, sin fastidiar, la sana moral y los sabios y prudentes consejos" (I, pág. 6). En efecto, como acabo de mostrar con un caso, son muchos los pasajes en los que se inserta la moral en la narración sin que ésta sufra; antes al contrario, el autor, con gran pericia, los hace surgir de ella, ofreciéndolos mediante el diálogo, lo que favorece el dinamismo del

4. En las Efemérides de España del 20 de Octubre de 1804 se comenta: "Puede decirse sin temor de equivocación que si no fuimos los inventores de los que los extranjeros llaman romances, que realmente es lo que conocimos bajo la denominación de novelas en los buenos tiempos de nuestra literatura, a lo menos se haría la mayor injusticia si se nos negase la gloria de haber sido los primeros que perfeccionamos este género" (pág. 1208).

5. Es verdad que éste comenta alguna vez, cuando se sabe que es español, que la suya, la católica, es la verdadera religión, pero no se pasa de ahí. Es decir, esta afirmación no lleva a negar las otras creencias ni a limitar la libertad de los otros personajes de pertenecer a la religión que deseen.

6. Esta reflexión de Martín de Bernardo-Mahamut tiene interés porque manifiesta una visión optimisma ante el progreso de la civilización y el logro de derechos individuales, civiles, de los "honrados ciudadanos", al tiempo que manifiesta una confianza sin límites en el papel previsor del Estado como benefactor del individuo. Esta idea manifestaría cierto alejamiento del tipo de relación monarquía-súbdito, para acercarse a la noción de estado civil, defensor de los derechos que el ciudadano va adquiriendo, que para la época ya era discutida por aquellos que cuestionaban los logros de la Revolución Francesa. 
relato y el pespectivismo a la hora de enjuiciar tanto los hechos como las costumbres de que se habla. El lector se va a encontrar, por tanto, con al menos dos perspectivas ante un mismo objeto o asunto, con lo cual podrá, en teoría, tomar partido por una u otra. Es cierto, sin embargo, que el discurso del sentido común y de los valores positivos es el que sale siempre vencedor, todo ello porque el escritor debe ser útil a su sociedad, necesitada "de una general corrección" (I, pág. 7), y en aras de una mejor educación de los lectores: "Hago causa general de todos los males a la primera educación y defectuoso amor paternal, cuyos modelos no habrán menester mis lectores (por nuestra desgracia) ir a buscar muy lejos de sus casas, si no fuere de sus personas. He aquí el objeto de mi obra: La educación hace felices o infelices, útiles o corrompidos, reinos y sociedades florecientes o débiles y desbastados (I, pp. 6-7) ${ }^{7}$.

\section{EL EMPRENDEDOR Y LA NOVELA DE AVENTURAS}

Una vez sentado que su objetivo es educar y entretener a los jóvenes mediante la "amena literatura", pues "jamás tuvo la lectura tanta aceptación en España como en estos tiempos" (I, pág. 3), resulta coherente que Martín de Bernardo elija para filtrar su "corrección" un método narrativo como es el relato de aventuras "verosímiles y pictorescas", trazado a través de un viaje. Esta fórmula narrativa, en tercera persona, le daba suficiente libertad para contar y ofrecer información sobre costumbres, geografía, relaciones sociales y personales, características regionales, etc., pero además, y puesto que el discurso tiene numerosas narraciones interpoladas en primera persona, podía también ofrecer análisis de sentimientos y relatos intimistas, con las ventajas que, para estos aspectos, tiene la narración en esta primera persona. De este modo, el autor se dotaba de los elementos necesarios para librarse de las limitaciones que impone la utilización de una perspectiva u otra y facilitaba su trabajo de presentar un mundo interior en contraste, no sólo un relato aparentemente superficial de aventuras. En este sentido, la tópica imputación al "género aventurero" de falta de hondura o de análisis, no es aplicable a El Emprendedor, que está a medio camino entre la novela de costumbres contemporáneas, la de aventuras y la sentimental, por el peso relativo que las pasiones tienen en ella. Repárese en que la ficción no puede existir sin la aventura, sea esta interior -el relato de una relación amorosa, el logro de una ambición, sea exterior -la búsqueda de un tesoro, de un amigo perdido- y que de esta forma, como motor de la aventura, utiliza Marín de Bernardo lo sentimental. En su novela no es el amor un objetivo en sí mismo, sino una forma de mediatizar su capacidad narrativa y de dotar a sus personajes de un calado ético y pasional que le permita hacer observaciones sobre la condición humana.

7. Esta reflexión se dramatiza en el relato en la persona del protagonista, quien comenta: "Diéronme maestros hábiles en todas materias, tanto de educación como de ciencias; en Jo primero salí aventajado a mis condiscípulos, ya puesto a caballo, ya esgrimiendo el acero, o ya en la danza y cortesanía; pero en las ciencias fui mediano, y aun no sé si hubiera llegado a sobresalir en alguna, mas el demasiado amor perjudicial de mis padres me distraía, teniendo a gracia mis travesuras en lugar de reprenderlas" (II, pp. 45-46). La crítica se dedica al estamento noble, al que pertenece Mahamut-Ramírez. 
La aventura amorosa le permite mostrar los cambios que sufre la mentalidad y el carácter de sus personajes; con la aventura exterior despliega sus conocimientos de todo tipo; y con ambas mantiene la atención del lector, ya mediante el interés de la acción, ya mediante el que despierta la búsqueda e hipotético hallazgo del objeto amoroso. Nada de lo que proponga Martín de Bernardo quedará sin respuesta, todas las dudas se resolverán a lo largo de la obra; se atarán todos los cabos siguiendo una de las condiciones de la novela de aventuras (Tadié, 1982. Véase también Bardavío, 1977). La novela de aventuras da lugar a presentar otras pasiones, como sucedía también con los relatos históricos, y a reproducir, por tanto, una imagen del mundo más real por total. El miedo, el coraje, la vanidad, la codicia, el deseo sexual, el amor y otras pasiones están presentes en El Emprendedor, así como las distintas actitudes que se pueden tener ante ellas. En este sentido, Ibrahim y Mahamut son sintomáticos de dos respuestas contrarias ante las mismas circunstancias. Tanto uno como otro son elevados de su posición originaria; Ibrahim, el esposo de Celima, se envanece y olvida a los que fueron sus amigos; Mahamut, por el contrario, se mantiene fiel a sus ideas primeras y comenta a sus compañeros de viaje, cuando sale de visitar a Ibrahim, ya encumbrado:

Debéis entender, amigos míos, que el variar los hombres de carácter, olvidar los beneficios recibidos, menospreciar las virtudes, parentesco, amistad y aun a sí propios cuando pasan de un estado mediano al pomposo rápidamente, es vicio tan antiguo, y de tanta extensión, que coge a todo el mundo, y del mismo modo que veis se conduce Ibrahim, se conduce el europeo más culto... (II, pág. 137).

Como se ve, la moral surge del relato de modo natural, pero también el perspectivismo del mensaje porque, si en ese momento Ibrahim es "estúpido señor turco" (II, pág. 136), antes colaboró en la salvación de Mahamut y de la ciudad de Basora: así pues, los personajes no son enteramente malos ni enteramente buenos, lo que sería un rasgo renovador característico de la nueva literatura dieciochesca. Los caracteres de los personajes son simples, reconocibles, pero cambian según lo proclives que sean a dejarse llevar por las pasiones o las circunstancias; característica que no suele ser frecuente en las novelas sentimentales ni en la literatura de tinte neoclasicista, donde la actuación de los personajes está muy codificada.

En otro plano, las diversas situaciones son pruebas a las que se enfrenta el protagonista, el héroe, en el que se han centrado todas las expectativas y que reúne las cualidades típicas de esta clase de protagonista: valentía, generosidad, habilidad. En relación con este aspecto del relato, Batjín señaló que "la idea de la prueba tiene también una importancia colosal en la novela puramente de aventuras. La productividad de esa idea se manifiesta exteriormente en el hecho de que permite combinar orgánicamente en la novela el aventurismo intenso y variado con una problemática profunda y una psicología compleja" (1989, pág. 205); profundas problemática y psicología que no se dan en $E l$ Emprendedor, pero productividad de la idea que sí aprovecha Martín de Bernardo, aunque sin llegar a grandes honduras. 
Así pues, lo griego de la novela de aventuras se presenta renovado, sin ajustarse a lo que eran los parámetros de dicho género, más que en el hecho de que los personajes viajan, cuentan sus historias y finalmente se reencuentran. No se ajusta, por tanto, a la definición que de este tipo de novela se conocía en la época y que Mesonero Romanos recuperó de tratadistas anteriores (Álvarez Barrientos, 1991, pp. 361-388) en su artículo La novela -resumen de su discurso de entrada en la Real Academia Española pocos meses antes-, aparecido en el Semanario Pintoresco Español, del 11 de Agosto de 1839: "Los que se propusieron reducir la novela al estrecho límite de una fábula de amor, y describir el sentimentalismo de una pasión exagerada luchando contra la adversidad o corriendo frenética hacia una perfección inconcebible, hubieron de fingir para ello una sociedad tan ideal, de exagerar caracteres tan falsos y adoptar un lenguaje tan exótico y plañidero" que se hace increíble a los lectores del día (pág. 254a-b). El Emprendedor no presenta una sociedad ideal, ni adopta caracteres falsos o exagerados, ni utiliza un lenguaje plañidero; sí reproduce a veces el llamado "estilo asiático", que quiere remedar los circunloquios y excesos retóricos de los turcos. Las actitudes de los personajes de Martín de Bernardo son modernas, propias del siglo XVIII, y los valores que presentan también, así como el tratamiento de los temas.

Por otro lado, hay un poso de tradicionalidad narrativa evidente, un ajustarse a ciertas convenciones literarias de la novela de aventuras como son las falsas muertes, la personalidad corajuda y varonil del protagonista, el empuje femenino, los malentendidos amorosos en el momento culminante de la narración, como cuando Mahamut va, por fin, a rescatar a Elisa, y otros que sólo muestran la maestría y el dominio de Jerónimo Martín de Bernardo al entender que una novela de aventuras no es un relato donde hay aventuras, sino uno donde lo principal es contar aventuras, de modo que sin ellas ese relato no existiría. Para ello da entrada al azar en el desarrollo de la narración, un azar controlado que, primero, saca a los personajes de su ambiente cotidiano, y después dirige caprichosamente su vida. Elisa y Mahamud abandonan su entorno habitual cuando son apresados por piratas en el mar; Ismael y Celfa cambian de vida cuando, causalmente, la segunda es objeto de un secuestro, y así sucesivamente. Éste es un asunto de cierta trascendencia filosófica e ideológica en la novela porque representa un paso más en el proceso de secularización de la cultura, de lo que se hizo eco la novela moderna dieciochesca muy a menudo. El azar suele denominarse "Divina Providencia", cuyas características son cada vez menos religiosas. Cierta identificación entre azar, destino y Providencia se percibe en el relato que parece relacionarse con otras manifestaciones de esta secularización, como es la teoría de la "mano invisible" -interpretación ya absolutamente laica del concepto de Divina Providencia- que presentó Adam Smith en La riqueza de las naciones (1776). El principio práctico y económico de que cuando el individuo actúa en su propio interés provoca consecuencias imprevistas (incluso negativas) que no estaban en su intención primera parece subyacer a esta narración. Un desengaño amoroso hace que Mahamut no quiera más trato femenino. El conocimiento, 
por lo demás accidental, de esta decisión por parte de Elisa desencadenará en ella el deseo de conocerlo y posteriormente el enamoramiento: es una consecuencia no pretendida por él, el efecto perverso de su acción. Más adelante, ya enamorados ambos, Mahamut no quiere perder a Elisa y la acompaña oculto en el barco. Esta actuación provoca un giro fundamental en su vida, al ser apresada la nave por los piratas y verse obligado a separarse de ella. A partir de aquí, la narración se sucede a golpe de azar, poniendo de relieve el hecho de que la aventura se encuentra al salir del ambiente habitual, al entrar en una civilización extraña. Se pueden señalar otros testimonios que avalan la presencia de la hipótesis de la "mano invisible" en la novela de Jerónimo Martín de Bernardo ${ }^{8}$.

Junto con el azar, el autor, además, juega con el suspense de una forma grata al lector, pues le anuncia desarrollos posteriores, encuentros que sospecha y le da pistas haciendo su lectura más grata: le concede, en definitiva, todas las ventajas, precisamente para que se confíe y pueda manejarlo a su antojo cuando desee sorprenderlo, como sucede con la aparición insospechada de algún personaje o con curiosas vueltas de tuerca narrativas.

\section{DIALÉCTICA CULTURAL: TOLERANCIA FRENTE A ESCLAVITUD}

La novela se inserta en el interés que por lo oriental se tenía en toda Europa durante el siglo XVIII y en el que pudo haber despertado la firma de tratados de paz con las distintas potencias árabes del Mediterráneo. Dejando a un lado las diferencias religiosas y culturales y los intereses económicos-que salieron beneficiados al remitir la piratería-, los sistemas de gobierno español y turco eran bastante semejantes, por cuanto ambos se basaban en el absolutismo. Martín de Bernardo no alzó la voz contra dicha forma de gobierno, aunque criticó la pereza de los otomanos y el excesivo protocolo del sultán, pero esto del mismo modo en que censuró a la nobleza mostrenca española. Desde esta perspectiva, hay que reconocer cierto parentesco entre El Emprendedor y obras como las Cartas persas de Montesquieu y las Cartas marruecas de Cadalso, aunque no en el formato narrativo. Interés tiene a este respecto el espacio, considerable, que dedica a tratar sobre la esclavitud. Otras novelas anteriores se habían ocupado del asunto. Al mismo tiempo, numerosos ensayos se publicaron en España en los años de entre siglos, contrarios al tráfico de esclavos. Jerónimo Martín de Bernardo se inscribe en esta línea, pero sin caer en el

8. La obra de Adam Smith fue traducida al español en 1794 por José Alonso Ortiz (Valladolid, Viuda e Hijo de Santander, 4 vols.). Una segunda edición, también en Valladolid y en 4 vols., se publicó entre 1805 y 1806 . A la "invisible hand" se hace referencia en el cap. 2 del lib. IV. La obra tuvo cierta difusión en España, siendo conocida por Campomanes, Jovellanos y otros. Se discutió sobre ella en la Academia de la Historia y en la Sociedad Económica Matritense. Para su recepción española, Schwart, 1990 y Perdices Blas, 1991. 
tópico del buen salvaje, ni en el sentimentalismo narrativo -el "lenguaje plañidero" de Mesonero Romanos-. Si acaso, cuando es Sísifa quien habla de su exclavitud, se permite cierta ingenuidad expositiva, puesto que cuenta la separación y muerte de su esposo. Léanse los siguientes fragmentos, en los que el autor une hábilmente la narración con la reflexión moral sobre diversos asuntos, evitando así que la carga didáctica dañe el estilo al interrumpir el ritmo narrativo:

Mahamut $[\ldots]$ pensaba en el valor que tienen sobre los mortales las primeras impresiones [...], casi imposibles de desarraigarse enteramente. Tal era la que tenía su esclavo de los árabes, a los que no podía mirar sino como a ladrones un negro, cuando éste mismo confesaba que su propio color era la causa de su esclavitud, opinión que sigue toda la Europa, África, Asia y América, no avergonzándose las naciones más cultas de incitar cuestiones y guerras en los países de estos infelices, para que entre sí se destruyan y se vendan, comerciando de estos racionales del mismo modo que con su oro, marfil y perlas... ¿Es posible que el hombre vea, palpe, guste y oiga la verdad, y que un error aprendido en su infancia triunfe de sus sentidos? [Repárese en el valor que se da al sensualismo y a la experiencia como forma de conocimiento, así como a la importancia de la educación]. ¿Que ha de conocer que la cercanía o separación del Sol es la causa del color de la piel, y que a pesar de estos conocimientos a ciencia cierta ha de atravesar los mares para venir (solamente, por un vil interés) a ultrajar la naturaleza? ¿Cómo ésta no desaparece antes de consentir estas ferias tan celebradas y consentidas en todo Oriente, donde el bárbaro mingrelio y circasiano comercia con sus hermosas hijas? (I, pp. 29-30).

La cita es peculiar por cuanto une argumentos científicos y sentimentales en su negación del esclavismo, algo poco frecuente en las novelas, no así en textos de carácter teórico. Pero reténgase que el autor parece responsabilizar de la esclavitud no sólo a los europeos, sino también a los asiáticos, americanos y africanos, cosa nada común en la narrativa de la época, que tendía a identificar al europeo con el esclavista y al negro con el esclavo, olvidando que entre los mismos negros africanos se practicaba el esclavismo antes de llegar los portugueses a las costas del continente, y que los árabes también tenían un floreciente comercio de esclavos.

Por otro lado, Mahamut, responsable de las reflexiones citadas, sólo da libertad a Alí al finalizar la novela, no antes, aunque algunas veces expresa su deseo de libertarlo, a lo que se opone el mismo negro. La libertad al terminar la novela es necesaria, tanto por el deseo del protagonista como por el hecho de alcanzar una situación nueva, de coordenadas distintas. También es obligada porque ha terminado el viaje, la experiencia. Para los esclavos, la consecuencia de su aprendizaje en esta novela de formación es su conversión al cristianismo y a los valores positivos occidentales que representa Mahamut -valores, por otra parte, de carácter universal, como el protagonista resalta en numerosas ocasiones a lo largo del relato-, así como su carta de libertad. Una nueva vida que simbolizan con el cambio de nombres - Alí pasa a llamarse Jerónimo, Aliatar, Estanislao y Xerif, Manuel-y con el matrimonio de los demás protagonistas, que también alteran sus nombres, como sucede, por ejemplo, en la 
novela intercalada de Ozmín y Daraja, en Guzmán de Alfarache (part. 1, lib. I, cap. viii) y en el Persiles y Sigismunda.

La otra cita - un desarrollo de la primera- es el testimonio de Sísifa, esclava, madre de Alí, que narra el episodio de su captura, con otros pormenores, ajustándose por cierto a las descripciones históricas de tales correrías:

En un reinezuelo de la abrasada África [...] nací; en paz vivíamos [...] hasta que vino a perturbarla un navío portugués, cuyo capitán [estableció] una factoría [...]. Trocaba sus espejos, cuchillos, vídrios, aguardientes y otras mil bagatelas, por nuestros marfiles, oro, perlas, canela, tabaco... [El portugués desencadena una guerra entre los reinos fronterizos para comprarles los prisioneros, y Sísifa y su esposo son apresados y vendidos al portugués, "que hacía granjería con su humanidad"]. Ved aquí el medio que han introducido los comerciantes para lucrarse, destrozando nuestras familias, y por esto mantienen la discordía entre nuestros caciques y reyes (II, pp. 162-164).

El tema de la esclavitud recorre la novela aunque no es el motivo principal de ella.

Merece destacarse también el perspectivismo con que afronta su anunciada imparcialidad a la hora de exponer las distintas culturas, manifiesto en la interpretación de hechos y situaciones. Esta perspectiva de acercamiento a la cultura árabe no le lleva a desdeñar costumbres sin antes razonar, ni a valorar una religión por encima de otra. Si alguna cultura sale desprestigiada es la occidental, por su trato de la esclavitud. Los beduinos, por ejemplo, aparecen como muestra positiva. El "anciano más respetable" conduce a los miembros de la tribu "por el sendero de la ley santa, y rectas y sencillas costumbres, tan religiosamente guardadas, que no han variado en tantos siglos [...]; por esta sólida base la paz, la justicia, la abundancia y la inocente alegría son inseparables de nuestros aduares; el lujo nos es desconocido, y todos los vicios que le rodean; nada deseamos, pues todo lo tenemos; no conocemos la libertad, porque no hay esclavitud" (I, pág. 39). Esta descripción idílica se complementa con otras en semejante dirección, pero también con la crítica de aquellos aspectos que al narrador le parecen censurables. Algo que también se hace con la cultura de los europeos. En este aspecto, es sintomático del relativismo que practica el autor el que, cuando uno de los personaje se disponga a narrar su historia, repare en la necesidad de que los demás conozcan antes las costumbres de su pueblo: "antes de que te refiera [mi historia] es necesario [...] darte a conocer el país, costumbres y carácter de sus habitantes" (I, pág. 168), pues sin estas nociones no podrá comprender el sentido de su desdicha ni encuadrarla adecuadamente, así como tampoco podrá explicarse la categoría del personaje, ni porqué sufre ante cosas que para otra civilización no tienen importancia. También destaca el narrador la tolerancia con que se conducen personajes de

9. Los portugueses solían desarrollar su comercio por la costa Oeste de África, no por el Mediterráneo, sobre todo en Guinea, reino de Benín y otros de la zona. 
distintas razas y naciones; naciones y razas que han mantenido tradicionales enfrentamientos, como son España y Francia y España y el imperio turco. Así repara en que en el barco del capitán francés viajan franceses, españoles (cuando se sabe que Mahamut lo es), árabes y turcos y, más adelante, vuelve a hacer hincapié en que "navegan gustosos e impávidos un español, dos árabes y un africano" (II, pág. 93). Desde luego, Mahamut tiene el protagonismo que le corresponde como héroe que es y, por consiguiente, la imagen de los españoles sale beneficiada, pero no debemos olvidar que durante gran parte de la nvoela no sabemos, aunque lo podamos sospechar, que Mahamut es español ${ }^{10}$. Al mismo tiempo, y aunque se haga algún elogio de los españoles (como en II, pp. 25-26), también se hace elogio de los representantes de los otros pueblos, como se critica cuanto hay de vituperable en las costumbres de las diversas naciones que comparecen en la novela. En realidad, el gran acierto de Martín de Bernardo en este aspecto es que no generaliza los rasgos de los pueblos -no hace a los personajes representantes de una nación-, sino que se refiere a individuos, lo que le permite presentar personajes matizados. De esta forma puede extraer conclusiones sobre el carácter humano, que atañen tanto a unos como a otros, porque hay conductas similares a unos y otros ante determinadas circunstancias, y así recuérdese el episodio ya aludido en el que Ibrahim se envanece tras ser elevado a una alta dignidad en Constantinopla. El texto continúa de esta forma:

Y del mismo modo que veis se conduce Ibrahim, se conduce el europeo más culto, sin que por esto se crea fue pasado este vicio de una a otra región, de este o aquel reino, o de esta o aquella provincia, pues el amor propio nace en el corazón del hombre, y donde quiera que hay hombre está él, y él le hace despreciador de su semejante, y por lo tanto orgulloso. Yo he conocido en mi tierra hombres que en la medianía eran discretos, humanos, amigos, sensibles y delicias de la sociedad, deseando tener bienes para socorrer al menesteroso; aumentarse su suerte, y volverse circunspectos; volar sobre ellos la fortuna, y tornarse ásperos, duros, crueles, desconocidos e ingratos, y tan inútiles como la seca arena al oficioso labrador, pues nada es más ingrato que el corazón del hombre una vez empedernido (II, pp. 137-138).

Aquí el autor hace uso del análisis perspectivista para mostrar cómo algunas conductas humanas que parecen locales son, en realidad, universales, dependientes sólo de la condición de la persona. Este relativismo, fundamental en la narrativa moderna, que Martín de Bernardo lleva adelante mediante la interpretación contrastada de las culturas y las actitudes, mediante la localización espacio-temporal de la narración y el enfrentamiento de los personajes, se completa con el perspectivismo de las situaciones, con la interpretación de los datos que marcan la diferencia entre la apariencia y la realidad.

10. Martín de Bernardo va dejando pistas y datos, según las convenciones del género, para que el lector sospeche que el protagonista es español, lo cual, por otra parte, intuye ya desde el título. 


\section{LA MORAL Y EL "CONOCIMIENTO DEL CORAZÓN HUMANO": LA APARIENCIA Y LA REALIDAD}

De este fenómeno hay un pasaje significativo, que consiste en la narración del encuentro entre Ibrahim y su padre, el cadí, cuando llevan algún tiempo sin verse, ya que el primero ha tenido que salir de Basora tras la revuelta, y se ha ocultado con el perseguido Mahamut y con Celfa, que ha dado muerte al agá, su esposo. La conversación que se desarrolla entre padre e hijo y el juego gestual que la acompaña, aparentemente contrario a las emociones que experimentan los personajes, es un alarde por parte de Martín de Bernardo de dominio de la técnica narrativa pero también de su capacidad para expresar literariamente sus observaciones del individuo. Ibrahim y su padre se sienten emocionados al reencontrarse, pero se mantienen a distancia, no se abrazan, en parte porque el cadí cree necesario mantener una actitud distante, de padre estricto, que disimule su emoción tras la ausencia injustificada de su hijo: “¿Eres Ibrahim? Sí, padre mío, responde éste algo cortado con el aire de irritado que fingía su padre. No, prosiguió el viejo, mi hijo se ha perdido o ha muerto, pues no hace caso de su padre [...]. Ibrahim, que amaba a su padre tanto como era amado de él, le tocó la mano, que el viejo retiraba contra su voluntad, y besándola le dijo con aire gracioso: Pues bien, si no creéis que soy yo el que ama a su padre [...], buscaré padre que no desconozca tan pronto a su hijo. Mientras decía esto volteaba entre sus dedos las borlas de su sable, como descuidadamente, y el padre, vuelto de costado, le miraba de soslayo, llena su alma de aquel gozo paternal que prueban los que tienen hijos virtuosos y adornados de gracias y valor, y en particular que saben mezclar la ternura al respeto con los padres, y así triunfan de sus enojos" (I, pp. 129-131. La cursiva es mía). La cita, quizá, fuera del contexto narrativo en que se da, no exprese con claridad lo que se quiere mostrar: que el autor ofrece, con palabras contrarias a los gestos, unas emociones aparentemente contradictorias con el aspecto exterior que presentan los personajes. Esta misma contradicción aparente entre palabras y actos o gestos, este disimulo, es el que en algunas ocasiones les libra de peligros, como sucede en el episodio en que Ismael es acusado en Suez de haber asesinado a un hombre (II, pp. 101-102), lo que había hecho, en realidad, aunque para salvar a Celfa y a Mahamut.

Esta cualidad de mostrar el disimulo sería otro rasgo moderno de la novela, propio de la literatura más avanzada del siglo, que entra de lleno en otro especto caracterizador de ella, la capacidad para hacer análisis del "corazón humano", para desentrañar lo que hay tras unas palabras o unos gestos determinados". La puesta en escena de las técnicas perspectivistas y relativistas, que caracterizó a la narrativa moderna del siglo XVIII, coloca la novela de Martín de Bernardo a gran altura en el panorama novelesco español de dicho siglo,

11. $\mathrm{M}[$ ariano de] $\mathrm{C}[$ arnerero] señalaba este rasgo al referirse a las novelas de Richardson: ¿Quién no conoce que dichas novelas las ha escrito una pluma maestra, pluma manejada por un hombre que había observado el corazón humano, y que poseía el maravilloso arte de pintarle, según es en sí, con caracteres indelebles y con aquel vigor que no todos poseen y conocen?", Memorial Literario, 10 de Mayo de 1805, pág. 168. 
pues pocos autores supieron utilizar esta técnica narrativa de forma tan solvente como él, quizá Valladares de Sotomayor en La Leandra y Mor de Fuentes en La Serafina, sean los mejores exponentes del uso de esa técnica (Álvarez Barrientos, 1991) ${ }^{12}$. Las relaciones que este recurso tiene con el objetivo educador y moralizante de gran parte de la narrativa dieciochesca es evidente, pues con esos análisis se pretendía dar a conocer al hombre, el movimiento de sus pasiones, lo que se denominaba el "corazón humano". La moral, en tanto que expresión de las conductas, de las actitudes, está por tanto presente en la narración, pero no de una forma que estorbe, sino integrada en el devenir novelesco, como ya señalé. La moral, así pues, se encuentra en las actitudes de los personajes, en sus acciones, en sus palabras y no en las digresiones del narrador, que no existen. Para autores como Valladares de Sotomayor y Martín de Bernardo la moral en la novela se plantea más que nada como un problema de estilo: se convierte en una preocupación estilística por cuanto se entiende que el elemento moral no debe romper el ritmo de la narración, y al mismo tiempo es una cuestión de verosimilitud, puesto que es la condición humana, la presencia y análisis de las pasiones, lo que está en juego.

\section{LO SUBLIME Y LA NATURALEZA. EL VALOR FORMATIVO DEL VIAJE}

Martín de Bernardo se vale del viaje, de geografías exóticas, para analizar las pasiones, no sólo la amorosa, sino también la ambición, la avaricia, la vanidad, la lujuria y otras. Este análisis se realiza a menudo sin que el narrador entre en la acción, sino mostrando cómo es cada personaje, tanto por lo que hace como por lo que dice. Recuérdese a este respecto, a Ibrahim, que comienza siendo un personaje positivo y acaba en el lado de los "malos", precisamente porque se deja llevar por la pasión. El autor apenas introduce comentarios al respecto, sino que deja que sean los propios personajes quienes reflexionen sobre ello; consigue así entrelazar en su novela la acción con lo que sería en principio propio de otras novelas más intimistas, la reflexión. El gusto que Martín de Bernardo tiene por contar una historia no le lleva a olvidar otros elementos que den más densidad a su narración y así, si nos ofrece las reflexiones y los comentarios enjundiosos de sus actores, nos regala también escenas donde describe batallas, peleas, fenómenos atmosféricos violentos, la naturaleza en estado sublime, en las que se muestra como un gran escritor. Tiene además otra virtud: consigue que su novela se lea de un tirón, a pesar de su extensión. Entre esas escenas violentas merece la pena destacar algunas y señalar además el detallismo con que las presenta, un detallismo que contribuye al realismo de su narración, tanto en estos casos, como cuando describe los edificios de Basora o Constantinopla. Un ejemplo: Malheureuse y Seib, su comprador, están en el desierto y el primero quiere aprovecharse de ella.

12. También Valladares dejó espacio a lo exótico y oriental en el tomo octavo de La Leandra, publicado en 1805, el mismo año que El Emprendedor. 
Ya iba a poner en ejecución sus depravadas ideas, cuando un hedor intolerable y el ronquido de los camellos le anunciaron esas horribles tormentas que en ese piélago de arena sepultan millares de caminantes. Un aire abrasador arrastraba ya las arenas y levantaba columnas de ellas en furiosos torbellinos. Seib quedó helado, aterrado y confuso, sin saber qué hacer; yo daba gracias a los cielos de su terrible socorro, no sintiendo acabar inocente. Los camellos, por su natural instinto, volvieron las ancas contra el aire, se echaron y escondieron sus cabezas debajo de su brazuelos. "Pereceremos sin duda, dijo Seib, ¡me castiga Alá! Sigamos, Celfa, el ejemplo de estos animales". Así lo hicimos. Dimos las espaldas al viento, nos cosimos contra la tierra pegados a los camellos, envolviendo nuestras cabezas entre nuestras propias ropas, que en este tiempo ya estaban anegadas de arena. Arreció con horribles bramidos el aire, se cubrió el cielo de nubes de arena, ocultando la luz del día, montes de ella pasaban sobre nuestras cabezas, contínuamente descargábamos su peso incorporándonos, pero de allí a un instante volvía a abrumarnos. Todo era horror, oscuridad, hedor, miedo, confusión y congoja; la muerte se prolongaba y cada bramido del viento y espeso remolino era el último que contábamos. El aire que nos limpiaba de la arena que nos cubría, nos levantaba muchas veces, y su pestífero y abrasado calor nos sofocaba, y no era bien pasado cuando ya volvíamos a estar cubiertos de la area que levantaba y caía tan espesa como lluvia de tempestad. En fin, después de dos horas de conflicto, un horrible trueno acabó de aterrarme, mas el camello, a quien estaba unida, sentí levantaba la cabeza; después un airecillo fresco me consoló, y ya no sentía tanto ardor ni tanta arena; el camello principió a moverse, destapé mi cabeza cuidadosamente y vi el cielo entoldado de espesas nubes, brotando fuego y retumbando truenos [...] Un trueno nos demostró el surco que un rayo iba haciendo por el suelo, inflamando la arena en vueltas y tornos, hasta que haciendo un remolino en ella se introdujo por el seno a extinguirse, a que siguió una lluvia menuda... (I, pp. 141-145).

Descripciones similares, caracterizadas por su vistosidad y visualidad, por el movimiento en la narración son las que dedica a la toma de la prisión en la que se encuentra Mahamut, al episodio de la doma de un caballo salvaje del sultán y, desde luego, las páginas en las que se describe la lucha de los protagonistas contra el mar para evitar que el barco, que tiene una vía de agua, se hunda (II, pp. 31-37). Son estas descripciones, que abundan en detalles tanto geográficos como urbanísticos, las que llevan a pensar que el autor conoció directamente la zona de Oriente en que sitúa su narración. El siguiente fragmento, necesariamente largo como el anterior, si se quiere dar una idea cabal del estilo de Martín de Bernardo, describe una tormenta en alta mar:

De repente un furioso viento arrancó de entre las jarcia del palo a un marinero, que estaba, como dicen ellos, tomando rizos a un vela, precipitándole al mar. Hombre al agua, hombre al agua, gritaron todos; se arrojaron cuerdas por todas partes para que se asiese, diligencias se hicieron para recogerle desde el buque, donde a la sazón se maniobraba contra el poder de los elementos. Tan pronto el huracán intentaba arrebatar la nave, como sumergirla el soberbio mar, para lo que amontonando montañas de agua una sobre otra las desplomaba contra el costado de la fragata, y luego elevándola sobre montes de espuma [...] Rechinaban las maderas, crujían los palos, arrancábanse los aparejos de ellos; todos [...] trabajaban [...], presto se vieron desanimados a la voz temerosa de uno de los calafates, diciendo que la bodega estaba llena de agua, que entraba por una rotura o tabla arrancada de la quilla por las olas [...]. En este estado, bramando el mar, silbando los aires encontrados y violentos, inmoble la fragata, tanto del contrario embate de los vientos como por el peso del agua que 
había recibido y seguía recibiendo, se acercó Mahamut al capitán, y le dijo: “ ¿No hay remedio, Vaumont?" "Nadie se atreve, le respondió desesperado, a bajar al mar y tapar con lanas y estopas las roturas de la quilla" "YY por qué tardáis en decirlo?, respondió Mahamut desnudándose. Vengan", prosiguió, haciendo otro tanto Ismael. Se traen lanas y estopas, se ata cada cual una cuerda a la cintura, toma cada uno una porción de lana, y se arrojan al mar como si les esperara tranquilo y en calma. Iguales a dos ágiles tiburones se calan al fondo, pero las encrespadas olas los separan del buque para estrellarlos contra él; venlos venir desde la cubierta, volteando entre la impetuosa ola [...], llega la ola espumosa, se rompe contra la nave, pero las manos de los valientes nadadores llegan antes, se aferran a la madera y aguantan su impulso $y$, saliendo por entre las espumas que deja, cogen más lanas [...] y se sumergen de nuevo, y suben ya uno ya otro aguantando los golpes de mar como rocas, hasta que una ola los arranca y aparta a pesar de sus fuerzas, pero, impelida por el aire contrario, los volvió contra la fragata con tal violencia que cuantos admiraban su valor, los creyeron hechos pedazos [...], la ola embrabecida, rugiendo como mil leones, se estrelló contra la mísera nao, llenando su cubierta de espuma y tronchando uno de los palos, que se llevó al mar... (II, pp. 31-35).

La descripción es buena muestra del estilo narrativo vigoroso, visual y plástico, del autor. Al mismo tiempo este y el ejemplo anterior presentan la naturaleza alterada, conceden espacio al sublime, en este caso, al sublime terrorífico. Lo sublime tiene cierto espacio en la narrativa que se publica en la España de finales del siglo XVIII. Algo he dicho en otro lugar sobre este respecto (Tójar, 1995), ahora quisiera señalar que la teoría de lo sublime también hace acto de presencia en esta novela, organizando, junto con lo pintoresco, la materia narrativa y otorgando a lo sentimental un lugar destacado pero no determinante.

En este sentido, convendrá recordar el éxito de El Valdemaro (1792), que tuvo varias ediciones, y que aúna los mismos elementos que El Emprendedor. Ambas se estructuran mediante un relato de viajes -si bien la geografía que se presenta en la novela de Martínez Colomer es imaginaria, mientras que la de Martín de Bernardo es real, aunque al final, imaginaria y exótica cumplan el mismo papel de alejamiento e irrealidad narrativo y de inserción en un espacio para la aventura-, en ambas hay también descripciones de la naturaleza en estado violento, hay pasiones importantes, como la ambición, centrando el relato, no sólo el amor; las dos comienzan in media res, de un modo que será habitual en la narrativa posterior, implicando al lector de forma inmediata en el mundo ficticio ${ }^{13}$; la moral y el didactismo, presentes también en El Valdemaro, no dificultan el relato; lo prodigioso aparece también en la novela de Martínez Colomer, aunque de distinta forma a como está en la de Martín de Bernardo: tiene gran efecto lo sobrenatural y terrorífico. Pero hay una diferencia notable respecto al carácter del protagonista: Valdemaro se deja poseer por las pasio-

13. Asi comienza la novela de Martín de Bernardo: "Entre los muchos que especulaban facciones, indagaban gracias, solicitaban habilidades y, sobre todo, buscaban hermosuras esclavas en el concurrido bazar o mercado de la ciudad de Basora, de la dominación otomana, el que más solícito las observaba era un turco joven de edad y noble porte, el cual, después de haber recorrido varias veces por entre turbas de charlatanes las hermosa víctimas de su comercio, se volvió a un negro, su esclavo, que llevaba un rico quitasol chinesco, diciéndole: "Vamos, Alí, no encuentro lo que tanto anhelo" (pp. 9-10) 
nes y por sus sentimientos hasta el punto de acariciar la idea del suicidio, mientras que Mahamut domina esas pasiones. Por otro lado, el objetivo de Martínez Colomer es similar al de Martín de Bernardo, en tanto que ambos muestran de qué forma han de tratarse las pasiones: dominándolas siempre para evitar las desgraciadas consecuencias a que suele llevar la demasiada sensibilidad.

Resulta interesante que dos de las más importantes novelas de la época se valgan, renovándolo, del modelo del viaje. Quizá no sea ajeno a la explicación de este hecho el magisterio cervantino que es posible rastrear en ellas. Tanto Los trabajos de Persiles y Sigismunda como el Quijote parecen resonar tras ambas novelas, sirviendo a los autores para sus peculiares narraciones. Incluso es fácil establecer un cierto paralelismo entre El Emprendedor y Persiles y Sigismunda en el episodio final del cambio de nombres de los personajes -ya aludido-. Persiles y Sigismunda resultan ser Periandro y Auristela, y se casan dando fin a un tipo de vida e iniciando otro (como los protagonistas de Martín de Bernardo). En ambos casos, dos relatos en los que el viaje estructura la narración y sirve para tener una experiencia de lo prodigioso, manifiesto en forma de lo exótico, de la aventura, del vencimiento de obstáculos e incluso de la propia experiencia sobrenatural, que en esta novela se tiene mediante el episodio del desencantamiento de la casa en Alejandría. El viaje sirve a los personajes para poner en orden su vida (frente al habitual desorden de la realidad que conoce el lector), pero al mismo tiempo es una forma de esperanza de la nueva vida que esperan iniciar si sus expectativas se realizan. El logro de éstas en la novela de Martín de Bernardo se patentiza en el reencuentro y en el posterior matrimonio; matrimonio que suele ser, por otro lado, uno de los recursos más utilizados para dar al lector la impresión de que los personajes cambian y, en El Emprendedor, los personajes cambian -no mantienen su carácter inalterable a lo largo del relato-, siendo ésta una de las características de la narrativa moderna, un manifestación del compromiso que se establece entre la literatura y la realidad que quiere imitar. Al mismo tiempo, el hecho de que los personajes cuenten su historia se relaciona con la necesidad de crear realidad, de dotar a esos actores de una vida, un pasado, que les dé entidad real. Un personaje que cuenta su vida se confiere densidad como individuo, muestra que tiene algo que contar.

\section{LO GÓTICO}

Lo prodigioso, lo gótico, de que he hecho mención más arriba, en El Emprendedor cobra forma de varias maneras. Por un lado, mediante la presentación sublime de una naturaleza alterada; por otro, gracias a la presencia de episodios mágicos. Es un uso de lo fantástico que entra de lleno en lo que se ha llamado "Io fantástico explicado", característico de cierta narrativa finisecular que encontró en Ann Radcliffe su ejemplo mejor. Martín de Bernardo se vale del episodio fantástico para interesar al lector en la narración pero sin perder la oportunidad didáctica que le ofrece. El episodio recuerda en principio un paso 
similar de la Vida de Torres Villarroel: los protagonistas han de desencantar una casa en Alejandría. Es un ejemplo de cómo lo racional, aplicado a casos aparentemente prodigiosos, puede desengañar, sacar del error. Se da el caso que hay un "mal genio" en una casa y que el bajá de Alejandría ha ofrecido una recompensa a quien la desencante. Los amigos de Mahamut quieren abandonar la ciudad, pero él "les hizo ver al ridiculez de tal creencia..., ilusión tan general, que en Europa tiene y ha tenido más crédulos, variando de nombres, y que particularmente en España se les llamó duendes o fantasmas, pero que la ilustración ha desterrado esta clase de embelecos" (II, pág. 109. La cursiva es mía). Los protagonistas se dejan convencer por Mahamut y acuden a la casa, de noche, con faroles y armas. Se suceden las escena de temor, de sucesos incomprensibles, ruidos, golpes, llamas, pero de ellas sale vencedora la valentía y racionaliadad del protagonista, que desenreda el caso y explica los prodigios, resultando que habitaban la casa unos fugitivos falsificadores de moneda que, para trabajar más a sus anchas, habían hecho correr el bulo del encantamiento. Se opone el mundo de la educación, de la ilustración, al de lo irracional.

En la novela, y más en la novela de aventuras, que avanza a golpe de sorpresa, de intriga, lo prodigioso en sus diversas manifestaciones es consustancial al relato. De esta forma, enfrentándose los personajes a diversos obstáculos -materiales, fantásticos o de cualquier otro tipo-, se convierte la novela de aventuras en novela de formación, en la que se potencia sobre todo al individuo, pues los actores, y también el lector, asisten al proceso mediante el cual pasan de un estado a otro, por lo general en el que adquieren nuevos conocimientos, necesarios para su vida, o toman la medida de sí mismos. Estos conocimientos tienen que ver más con las pasiones humanas que con otra cosa, aunque en El Emprendedor también tengan cabida los hechos comprobables, sobre todo lo referente a las costumbres orientales. Estos nuevos conocimientos, la experiencia adquirida, son los que les van a servir para su vida futura, que en la novela se simboliza mediante el casamiento de los personajes, cumpliendo así otra de las convenciones de la novela de aventuras: nada debe quedar sin solución, ningún cabo suelto, todas las historias deben tener un final. Precisamente, el que Cervantes no terminara "formalmente" las historias de todos los personajes de su Quijote fue la razón de que a lo largo del siglo XVIII, y aun después, se escribieran tantas continuaciones, que pretendían agotar la vida de los personajes.

\section{LA AMISTAD, VALOR ILUSTRADO}

Martín de Bernardo da fin a su obra mediante las bodas y consigue coherencia en el relato, pues el final que da a las expectativas de los personajes es el objetivo al que dirigía toda la acción. De ese relato se sigue el valor de la fidelidad, tanto amorosa como amistosa. Los protagonistas se buscan y no tienen dudas en cuanto a la reciprocidad de sus sentimientos -aunque Mahamut y Elisa sí las padezcan hacia el final de la novela, consiguiendo un efecto 
retardatario de la acción de gran eficacia-, pero más importancia tiene la fidelidad entre amigos, el agradecimiento que une a lo largo del relato a Mahamut, Ismael, Celfa y Alí. Esa fidelidad sostiene el edificio ético de la novela y es la que hace que en torno al protagonista se agrupen personajes de diversas procedencias étnicas, de distintos estratos sociales, y se mantengan unidos gracias a los valores de amistad, tolerancia, solidaridad y fidelidad que Mahamut ejemplifica. Los actores son felices en la medida en que contribuyen a la felicidad del otro. Su interés personal, en un rasgo netamente ilustrado, se acopla al de la comunidad, en este caso, de amigos que viajan juntos.

Esta fidelidad amistosa se da también entre mujeres y hombres, de hecho el que Celfa viaje vestida de varón, sea corajuda, valiente, sepa disparar sus pistolas -y las dispare-, la coloca al mismo nivel que sus compañeros, de manera que comparte sus mismos valores de camaradería ${ }^{14}$. Pero esto no hace olvidar la disputa entre sexos, y así vemos cómo existe en la novela una unión entre las mujeres, más allá de su condición individual, que las hace ser fieles a su sexo. Martín de Bernardo nos las presenta en conjunto de forma más positiva que a los hombres, lo que coincide con el discurso moderno del siglo XVIII, que entiende a la mujer como civilizadora del hombre y como su igual, al menos en algunos aspectos (Álvarez Barrientos, 1995). Por otra parte, el papel que tiene la mujer en las distintas culturas oriental y occidental le sirve al autor para reflexionar sobre la condición femenina y su función en la sociedad. Esto es lo que lleva a Celfa a exclamar: “¡Oh, feliz país, donde las mujeres se hacen respetar con la menor acción..., en tanto que la infeliz asiática obedece, sufre y se encierra para tan solo mirar a su tirano dueño...!" (I, pág. 156). Y esa misma observación de las costumbres respecto al trato con la mujer le permite al narrador señalar diferencias culturales, no sólo entre Oriente y Occidente, sino incluso entre Francia y España, como sucede con los episodios en que comparece el capitán francés, en los que comentan ciertas peculiaridades francesas en el trato con las damas. Esta capacidad discriminatoria es, por otra parte, una condición del viajero o del aventurero, ya que está en una situación ideal para observar desde fuera las costumbres y la vida en general.

Así pues, la novela articula diversos elementos de la tradición narrativa más esencialmente novelesca, como es la de la novela de aventuras, con otros nuevos que ponen al día dicha tradición y la revitalizan al dotarla de contenidos ideológicos modernos, contemporáneos al lector de finales del siglo XVIII y comienzos del XIX. El condicionante didáctico se disimula en un relato exóti-

14. Cuando Ismael y los criados de Mahamut vayan a liberarlo a la cárcel, Celfa no admitirá quedarse inactiva esperándolos: "No..., quiero acompañarle, participando de tu peligro y del honor de hacer algo por nuestro bienhechor. Yo no le soy menos agradecida, ni menos deudora. Iré, te acompañaré, te defenderé y no me separaré de tí. Corazón tengo, y espíritu bastante para disparar una pistola, venga una vestido que me disfrace algo y marcharemos juntos" (I, pp. 104-105). Ya disfrazada, Ismael no se cansará “de ni:ar la agraciada figura que hacía Celfa vestida de hombre, pues más parecía al niño amor, cuando va a herir corazones sorprendidos por su belleza, que a un guerrero que va a arrostrar peligros" (I, pág. 105). 
co donde se ofrecen contenidos éticos de diversa índole sin entorpecer la narración, asistiendo el lector al aprendizaje de ese mensaje ético mediante la contemplación de las actitudes de los personajes y la lectura de sus palabras. En este sentido, la novela de formación que es toda de aventuras, no nos muestra en El Emprendedor un héroe vacilante que aprende a medida que comete errores, sino a un personaje ya formado en valores sólidos que es sometido a pruebas de las que sale triunfante, con lo que se refuerzan los valores e ideales que encarna, lo que sería uno de los aspectos más conservadores de la novela. Las dudas, los altibajos, las tentaciones, las muestras de debilidad, que serían rasgos de una narrativa moderna, están, por el contrario, en los otros personajes, como ya he mostrado.

\section{RECEPCIÓN CRÍTICA DE LA NOVELA EN LA ÉPOCA}

El Emprendedor se anunció en la Gaceta de Madrid el 23 de Agosto de 1805, con este certero comentario:

Esta novela original, en que el autor se aparta de la monotonía común en las obras de este género, reúne la novedad, el interés y la verosimilitud a una dicción correcta y castiza, y hermana justamente el recreo de una lectura amena con la instrucción y los principios de una moral sana (pág. 732).

Un mes después, el 20 de Septiembre, la novela obtenía una interesante e irónica reseña de un tal Cándido Faura en el Memorial Literario. En la "Carta a los editores del Memorial Literario acerca de la novela original titulada $E l$ Emprendedor, o aventuras de un español en el Asia", fechada en Cuenca el 10 de Septiembre, se repara en que la obra, en contra de "la dicción correcta y castiza", ha sido escrita con atropellamiento y poca corrección y, en efecto, repeticiones de palabras y ciertas incoherenias, que una revisión detenida habría evitado, salpican y afean el relato. Ahora bien, el comunicante se ve en la obligación de reconocer que, como la variedad es lo que más agrada en este tipo de obras, "el autor la ha sabido dar a la perfección, y esto sin disputa ninguna" (pág. 366). Parece que a Faura le gustó la novela, pero sintió ciertos escrúpulos clasicistas que le llevaron a oponer los valores de la preceptiva a los de la novela: "perdonen [...] si siempre me voy a buscar a Horacio y Boileau, porque me gustan más que El Emprendedor, y eso que me gusta mucho" (pág. 369). Comenta también, con reminiscencias orientales, que "los mil y un personajes que hablan en esta novela son interesantísimos" (pág. 367; las cursivas siempre son suyas); que "acción, episodios, caracteres, costumbres, estilo; todo, todo es maravilloso" (pág. 366), para añadir inmediatamente que los incidentes no son muy verosímiles, ni los personajes están muy bien sostenidos. Hay que llamar la atención sobre el hecho de que los personajes hablen. Quizá sin pretenderlo, el crítico repara en una característica de esta novela: las voces narrativas que evitan la injerencia del relator. 
En su misma línea de decir y desdecirse, Fauca comenta que las descripciones son "vivas y animadas [...], tomadas de la misma naturaleza" (pág. 369), para señalar que "en esta novela se quebrantan a cada momento las reglas del buen gusto y del arte" (pág. 368). "iQué importa!", exclama, si "lo mejor de todo es dejar correr la imaginación, para que luego los jueces imparciales comparen la obra a la naturaleza agreste, que en su mismo desorden y confusión presenta mil perspectivas asombrosas y magnificas" (pp. 368-369).

Como se puede concluir tras la lectura de la carta y la observación de aquellos conceptos que Cándido Fauca subraya, el autor enfrenta dos estéticas: una, la de Boileau y Horacio, que le gusta más, y otra, más moderna, que se basa en la observación de la naturaleza, agreste, variada y confusa, que presenta diversas perspectivas, y que también parece gustarle, a su pesar. Esta última encarnó en numerosos escritores que tenían un concepto moderno de la imitación artística y que privilegiaban el genio frente a las "reglas del buen gusto y el arte". El crítico termina su comentario incidiendo sarcásticamente en la originalidad de la obra, "tan original que nadie puede disputar su originalidad, y la España se gloriará de poseer una obra tan particular para modelo de noveladores" (pág. 374). La observación es, desde luego, irónica, pero lo es mucho más porque incide en algunos de los objetivos que Martín de Bernardo se proponía en su prólogo (que ya han sido comentados). Creo que gran parte de la inquina que muestra contra la novela y la protesta de originalidad de Martín de Bernardo se debe a que considera El Emprendedor como una simple novela griega y no llega a apreciar sus valores y novedades. Esto sin menoscabo de que bajo el nombre de Faura se esconda algún enemigo literario del autor, o algún traductor.

En consecuencia, para Cándido Faura, Martín de Bernardo no consigue las miras que perseguía sino una obra objetable porque no se ajusta al prontuario neoclasicista, aunque tenga que reconocer, implícitamente, que la novela sí responde a los requisitos propios de dicho género.

Ese mismo mes, el 25 de Septiembre, se vuelve anunciar, esta vez en el Diario de Madrid, y el texto que acompañaba el anuncio daba pie a una pequeña diatriba acerca de su valor, pues la relacionaba con el Persiles de Cervantes, lo que había de desencadenar polémica. Decían así los redactores:

En un tiempo que nada menos se trata de impugnar que las obras del inmortal Cervantes [se refiere a la polémica del Anti-Quijote], se presenta al público esta novela de costumbres y viajes, y en la que el autor se jacta de haber intentado acercarse lo posible al lenguaje de las aventuras de Persiles. El espíritu de traducción (por decirlo así), tiranizando el talento de nuestros literatos, no le ha arredrado para escribir este original, único tal vez en muchos años a esta parte, lleno de cuadros, exacta geografía y usos diferentes (pp. 62-63).

En este anuncio como en el anterior se hace referencia, con acierto, a los valores de la novela: interés por las costumbres y la verosimilitud, pero en este segundo se dice que el autor se jacta de acercarse al Persiles. Lo cierto es que 
Martín de Bernardo no alude a ello en su relato, ni en el prólogo, por lo que, o ésta era una apreciación personal del redactor del anuncio, o el autor lo confesaba en conversación personal, ya que, de figurar por escrito, a Faura no se le habría escapado este suculento punto de ataque. Lo cierto es que en otro anuncio, publicado por las misma fechas, esta vez en las Variedades de ciencias, literatura y artes (tomo IV, $\mathrm{n}^{\mathrm{O}}$ 19, de 1805), se vuelve a hacer la comparación con el Persiles:

Nos atrevemos a felicitar al autor no sólo por las bellezas que observamos en el plan, y en el enlace de su obra, sino también porque manifiesta haber tenido siempre presente al célebre autor del Persiles y Sigismunda, y aun haberle seguido con acierto en diferentes pasajes (pág. 62).

Esta vez la comparación no se le achaca al autor, sino que resulta de la lectura de la novela. El redactor del anuncio-juicio continúa celebrando el resultado: "además de la verosimilitud y del interés, que resaltan en toda la novela, hallamos caracteres bien demarcados y sostenidos, una novedad agradable en las noticias históricas que se presentan en varios episodios, y en toda la acción principal".

Estas observaciones, que son acertadas, como he intentado mostrar a lo largo del presente artículo, fueron negadas inmediatamente, de forma gratuita, desde la Minerva o el Revisor General, de los días 25 y 29 de Octubre ${ }^{15}$. El crítico se valía del recurso del sueño, y lo cierto es que, antes de entrar en materia, ofrece un relato de ficción prácticamente surrealista, lleno de asociaciones libres, que tiene más interés que la propia reseña negativa. Primero desacredita la novela de forma general, sin razones y de forma injusta ${ }^{16}$, y luego señala: "a qué es tomar en boca al Persiles, novela realmente original, por su feliz enredo y su excelente lenguaje, hablando de un cuento estrafalario, cuyo enredo es solo un confuso embrollo, y cuyo lenguaje es el más miserable que en estos tiempos se ha usado" (pág. 65).

Desde luego, esta alusión al lenguaje tiene interés porque, dejando a un lado los errores y las repeticiones, así como la opinión de otros críticos, Martín de Bernardo lo emplea con intención poética para dar brillo a su relato, intención que unas veces le lleva a cometer graves errores y otras a ofrecernos un texto lleno de sorpresa y aciertos léxicos. Es también cierto que seguramente buscaba redondear un ambiente vistoso y "arábigo", como de hecho señaló en el prólogo.

Cándido Faura terminaba su reseña insistiendo irónicamente en la originalidad de la obra. Desde luego, lo original no está en la utilización de un modelo narrativo tan antiguo como los orígenes del propio género, sino en algo que él

15. Agradezco a la profesora Inmaculada Urzainqui que me diera noticia de esta reseña de $E l$ Emprendedor.

16. Contra el anuncio en la Gaceta y en el Diario escribe: "si esta obra es original, lo es sólo en lo malo; el plan es trivial, si ya no copiado de otra novela; está muy mal enlazada; ninguna verosimilitud, poco interés, menos novedad y verdad en las descripciones, costumbres y caracteres" (pág. 65). 
no supo o no quiso ver: en cómo ese modelo antiguo se reutilizaba, renovándolo al unirlo con el biográfico y el de la moderna literatura de viajes, lo que permitía abrir el género a las expectativas nuevas de los lectores: el realismo narrativo, frente a la idealización anterior, sin dejar fuera de este relato cosmopolita lo que de irracional hay en la experiencia humana, ya sea mediante lo fantástico, ya mediante la consideración de conductas extremas.

Si se ajustaba a algunas convenciones del género bizantino, como la disimulación de la identidad de los personajes, la separación de los amantes, su fidelidad a pesar de todo, no respetaba otras, como aquélla que suponía cierta delectación en episodios que no hacían avanzar el relato. A fin de cuentas, Martín de Bernardo está escribiendo una novela de aventuras y lo que necesita es acción. Aunque se encuentren reminiscencias de la narrativa española de tema morisco, como he señalado, son más las novedades que aporta que sus débitos con esa tradición. Si Voltaire parodió la novela de viajes y aventuras en Cándido, lo que significaba una cierta revalorización y puesta al día, Martín de Bernardo renovó la antigua escritura de este tipo de relato, consolidando la aventura como medio, y demostrando que esa antigua estructura era/es sumamente productiva y servía a sus objetivos de escribir una novela que lograra el aprecio de los lectores, pues mostraba de manera sólida algo de mucha repercusión en la narrativa moderna y contemporánea: de qué forma el espacio condiciona al personaje.

\section{REFERENCIAS BIBLIOGRÁFICAS}

ÁLVAREZ BARRIENTOS, Joaquín. 1991. La novela del siglo XVIII, Madrid, Júcar.

- 1995. "El modelo femenino en la novela española del siglo XVIII", Hispanic Review, 63 , pp. 1-18.

BARDAVÍO, José M"*. 1977. La novela de aventuras, Madrid, SGEL.

BATJÍN, Mijail. 1985. Teoría y estética de la novela, Madrid, Taurus.

GARCÍA BERRIO, Antonio y HUERTA CALVO, Javier. 1992. Los géneros literarios: sistema e historia, Madrid, Cátedra.

LAFARGA, Francisco. 1994. "Territorios de lo exótico en las letras españolas del siglo XVIII", Anales de Literatura Española, 10 (1994), pp. 173-192.

MARTÍNEZ COLOMER, Vicente. 1985. El Valdemaro, ed. G. CARnERo, Alicante, Inst. Juan Gil Albert.

PERDICES BLAS, Luis. 1991. La "Riqueza de las naciones" y los economistas españoles, Madrid, Univ. Complutense.

SCHWARTZ, Pedro. 1990. La recepción inicial de "La riqueza de las naciones" en España, Madrid, Univ. Complutense.

TADIÉ, Jean-Yves. 1982. Le roman d'aventures, París, PUF.

TÓJAR, Francisco de. 1995. Cuentos morales y La filósofa por amor, ed. J. Álvarez BarRIEnTos. Cádiz, Universidad. 